\title{
Serology and Amplicon Deep Sequencing of MSP1- Block 2 Haplotypes as New Tools for Plasmodium Vivax Infections
}

\section{Elizangela Farias}

ILMD Fiocruz Amazônia: Instituto Leonidas e Maria Deane Fiocruz Amazonia

Maele Jordão

ILMD Fiocruz Amazônia: Instituto Leonidas e Maria Deane Fiocruz Amazonia

\section{Ricardo Avila}

Universidade do Extremo Sul Catarinense

\section{Mirian Fagundes}

Universidade do Extremo Sul Catarinense

\section{Paulo Feuser}

Universidade do Extremo Sul Catarinense

\section{Victor Souza}

ILMD Fiocruz Amazônia: Instituto Leonidas e Maria Deane Fiocruz Amazonia

\section{Felipe Naveca}

ILMD Fiocruz Amazônia: Instituto Leonidas e Maria Deane Fiocruz Amazonia

Paulo Afonso Nogueira ( $\nabla$ paulo.nogueira@fiocruz.br)

Fundacao Oswaldo Cruz https://orcid.org/0000-0001-9677-7225

\section{Research Article}

Keywords: Plasmodium vivax, amplicon deep sequencing

Posted Date: December 16th, 2021

DOI: https://doi.org/10.21203/rs.3.rs-1160593/v1

License: (c) (1) This work is licensed under a Creative Commons Attribution 4.0 International License. Read Full License 


\section{Abstract}

\section{Background:}

Relapses of Plasmodium vivax ( $P$. vivax) infections are major causes of malaria morbidity, and tools for distinguishing relapses from reinfections are needed in malaria endemic areas.

\section{Methods:}

Herein, a panel of plasmas of $72 P$. vivaxinfected pregnant women, of whom 31 had had at least a recurrence of $P$. vivax infection, was used in a serology for IgM and IgG against 6 P. vivax-merozoite surface protein-1 ( $P$. vivax-MSP1-Block 2) haplotype-specific peptides, in order to identify re-expositions to same haplotypes in the recurrences during the pregnancy. In parallel, we used the amplicon deep sequencing (ADS) with $P$. vivax-MSP1-Block 2 amplicons of the in eight blood samples of non-pregnant $P$. vivax-infected patients to identify multi or monoclonal infections based on MSP1-Block-2 haplotypes, and to quantify the reads of different haplotypes between those with multiclonal infections. We synthetized a new panel of overlapping peptides mapping each one of the six P. vivax-MSP1-Block 2 haplotypes and we validated with new IgM and IgG serology.

\section{Results:}

Most pregnant women presented IgM that recognized more than one peptide, thus indicating multiple infections by $P$. vivax-MSP1-Block 2 haplotypes. The same IgM anti-peptides remained in several women in the recurrent episodes most likely indicates re-exposure to the same haplotype of MSP1 Block 2. The $\lg G$ reactivity the $\lg M$ to $\lg G$ switch were low.

The ADS using next-generation sequencing (NGS) identified multi- and monoinfection by $P$. vivax-MSP1Block 2 haplotypes. Of eight patients, two of them had had the first $P$. vivax-infection. Monoinfections with $P$. vivax-MSP1-Block 2 haplotypes were observed in two prime-infected patients and three of patients with previous malaria. In all $P$. vivax-MSP1-Block 2 haplotype-monoinfected patients, the reactivity of IgM was observed only against overlapped peptides of the same haplotype detected in ADS, while for IgG, no reactivity was observed for any of the peptides of the same haplotype or the others.

We were able to identify multiclonal infections through three haplotypes of $P$. vivax MSP1 Block 2 in three remaining patients, among which, there was always one majority haplotype that predominated with more of $95 \%$ of high-quality reads. The levels of haplotype-specific IgM in the serology correlated with the read ratios of each haplotype, but IgG levels not, including in one of the multiclonal infections, a minority haplotype was recognized with higher levels of $\lg G$ than that of the majority one.

\section{Conclusion:}


Our findings suggest that the combination of ADS and serology for $P$. vivax-MSP1-Block 2 haplotypes may be used as a new tool for distinguishing reinfections from relapses in malaria.

\section{Background}

Relapses of Plasmodium vivax (P. vivax) infections are common and frequent, especially in subjects not treated with anti-relapse therapy. The term "relapse" describes recurrences of malaria derived from persistent liver stages of the parasite (hypnozoites), which arise after the "awakening" of these hypnozoites and the subsequent intrahepatic schizogony followed by blood stage multiplication [1]. In the Tropics, $P$. vivax relapses occur by a short latent period approximately 3-4 weeks after plasmatic concentrations of antimalarials decrease. In temperate regions or in parts of the sub-tropics, late relapses succeed after a long-latency period, approximating 8-10 months from primary $P$. vivax infection [2]. In South America and India, late and short interval relapses may occur, thus it is difficult to discriminate a reinfection of the true relapse $[1,3]$.

Nicholas J. White proposed an interesting mechanism to explain the relapse activation of $P$. vivax [1]. In a malaria endemic area, at the time of infection (sporozoite inoculation) some individuals often already have hypnozoites of different genotypes that were acquired in previous inoculations. In this newly acquired infection, one part of them develops into pre-erythrocytic schizonts, and another becomes dormant as hypnozoites. The disease associated with infection of the blood stage activates a small fraction of the previously acquired hypnozoites, and one hypnozoite of each genotype is activated by the disease, evolving into the respective pre-erythrocytic schizonts that will be later transmitted. Since a single inoculation of $P$. vivax can cause multiple relapses [4], new tools for assessing $P$. vivax relapse in clinical studies need to be developed.

Despite relatively low-level transmission, populations of $P$. vivax exhibit great genetic diversity since many alleles circulate on one population level, and individuals commonly harbor multiple genetic variants at the same time [5]. Genotyping of $P$. vivax using microsatellite markers provide assess the population structure of these parasites [6-8]. However, their hypervariability may be less useful for longitudinally comparing individual genotypes within subjects in search of recurring variants [9]. Moreover, distinguishing relapses from reinfections has been confounded by the frequent finding of genetically different parasites at relapse, and different microsatellite alleles may be closely-related parasites $[3,5$, 10-13].

Amplicon deep sequencing (ADS) for highly polymorphic molecular markers has become an innovative tool for identification of multiclonal of infection as well as exploring genotypic patterns to discriminate relapse from reinfection. High-throughput next-generation sequencing technology (NGS) enhances the detection of the predominant variants and also that of the minority variants, thus providing a framework for determining the likelihood of re-infection and relapse [5]. Merozoite surface protein 1 (MSP1) is the most abundant surface component of merozoite. The single-copy MSP1 gene has six highly polymorphic domains (called polymorphic blocks) flanked by highly conserved sequences with stable frequencies in 
parasite populations [14-18]. Block 2 is the most polymorphic and has been used in studies of genetic diversity with its ortholog in P. falciparum [15, 17, 19-21]. In addition, Block 2 MSP1, identified by immunological analyses, is one of the main targets of human immunity to malaria [16, 20, 22-29].

In this context, the investigation of the seroprevalence of a genetic parasite marker may represent a new approach for identifying relapses, as well as in understanding the biology of the reactivation of hepatic latent forms (hypnozoites). In pregnant women, repeated episodes of malaria during pregnancy is relatively common due to relapses, since primaquine cannot be administered during pregnancy as the glucose-6-phosphate dehydrogenase (G6PD) status of the fetus is unknown [7, 30-32]. Herein, we tested for seroprevalence of IgM and IgG in pregnant women infected with $P$. vivax against a panel of peptides generated from the main haplotypes of Block 2 of $P$. vivax. Since these patients were followed up until time of delivery and had repeated episodes of $P$. vivax malaria, we evaluated whether the persistence of anti-haplotype IgM may indicate exposure to the same parasite populations in repeated episodes.

After validation of the peptide serology for prevalence of haplotype-specific antibodies, we used amplicon deep sequencing in NGS based on the haplotypes $P$. vivax Block 2 to determine multiclonal infections in non-pregnant patients and quantified each haplotype population. With a panel of superimposed peptides for each haplotype, we evaluated whether haplotype-specific IgG levels are correlated with the parasitic load of each haplotype. We hypothesized that use of two methodologies haplotype-specific Block 2 serology and deep sequencing of the MSP1 Block 2 PCR product may be innovative strategy for evaluation of relapses and reinfection in malaria by $P$. vivax.

\section{Material And Methods}

Serums from pregnant women with malaria. A total of 72 pregnant women with malaria were recruited from a Biobank and subjected to serology against peptide variants of $P$. vivax MSP1 Block 2. These samples were obtained from an observational cohort study in five municipalities (Cruzeiro do Sul, Mâncio Lima, Rodrigues Alves, Marechal Thaumaturgo and Porto Alter) in the Juruá Valley, located in the state of Acre, Brazil (western Brazilian Amazon) [33-35]. This region is considered highly endemic for malaria, with an annual parasitic incidence (API) that is over 100 cases per 1,000 inhabitants. The Juruá Valley is also characterized by a significant prevalence of $P$. vivax infections, which are responsible for $70-80 \%$ of all malaria cases $[25,26]$. These women were followed up between January 2013 and April 2015, until the birth of the child, which involved at least two home visits in the second and third trimesters to monitor the clinical status and collect a peripheral blood sample, in addition to the usual prenatal consultation. Of the 72 women, 41 had only had one malaria episode during pregnancy, 17 had a new malaria episode, and 14 had two or more episodes of malaria in the second and third trimesters. The diagnosis of vivax malaria was performed by microscopy of the thick and thin smears of peripheral blood and later confirmed by PCR. An additional blood sample was collected with each episode of malaria during pregnancy, by which malaria infection was confirmed by microscopy and PCR. Serum samples from 10 individuals with no history of malaria were used as controls, in accordance with the study by [34]. 
Blood samples of patients with malaria. For amplicon deep sequencing analysis, sediment samples of red blood cells and plasma were obtained from seven patients diagnosed with malaria by P. vivax. These were collected at the Tropical Medicine Foundation Dr. Heitor Vieira Dourado (FMT-HVD), which is tertiary care center for infectious diseases in Manaus, capital of the state of Amazonas, Brazil (Central Amazon). An aliquot of $10 \mathrm{~mL}$ of peripheral blood was collected immediately after confirmation of monoinfection in the thick blood smear by microscopy specialist. The peripheral blood of five residents of Manaus with no previous history of malaria was also collected as healthy controls.

Sequence alignment of $P$. vivax Block 2. We selected sequences of $P$. vivax MSP1-Block 2 from different malaria endemic regions around the world that are deposited in GenBank. The EditSeq program was used to edit the amino acid sequences, and the alignments were performed using the Megalign programs of the DNAStar package (Lasergene, version 4.05).

Prediction of linear epitopes of $B$ cells and peptide synthesis. Predictions of epitopes of B cells were performed on 24 amino acids from P. vivax MSP1-Block 2 using the BepiPred 1.0 server. Synthetic peptides were synthesized in the solid phase using the Fmoc strategy (9-Fluorenil-metoxicarbonila-link). Final cleavage and deprotection were performed using the gradient method, which combined trifluoroacetic acid (TCA)/water/1,2-ethanodithiol/triisopropylsilane. After elution in aqueous acetonitrile, they were purified by reverse phase chromatography on a Sephasil@ C8 peptide column in high performance liquid chromatography. The elution was performed using the acetonitrile-TCA gradient method and absorbance was monitored at $280 \mathrm{~nm}$.

Enzyme immunosorbent assay. The enzyme immunosorbent assay (ELISA) was performed using high binding microplates (Costar, Cambridge, MA, USA) coated with peptides ( $200 \mathrm{ng} /$ well). The plates were incubated at $4{ }^{\circ} \mathrm{C}$ overnight and washed four times with phosphate-buffered saline solution with Tween 20 at $0.05 \%$ (PBS-T). PBS-T containing skim milk was used to block (4\%) and dilute plasma and antibodies (1\%). Each plasma sample $\left(50 \mu \mathrm{L} /\right.$ well) was diluted to $1: 200$. After a 1-hour incubation at $37^{\circ} \mathrm{C}$ and four wash cycles in PBS-T, secondary antibodies were added and incubated for 1 hour of incubation at $37^{\circ} \mathrm{C}$. HRP-conjugated mouse monoclonal antibodies, anti-human IgG (IG266) and anti-human IgM of HRP-conjugated mouse (ICL-931) (Novus, Cat \# NBP2-34648H and NBP1-42268h, respectively) were added at a dilution of 1:3,000. The enzyme-substrate reaction was developed with tetramethylbenzidine $(\mathrm{TMB}) / \mathrm{H}_{2} \mathrm{O}_{2}$ at room temperature (dark). After 10 minutes, the reaction was stopped with $2 \mathrm{~N} \mathrm{H}_{2} \mathrm{SO}_{4}$. Absorbance values were measured at $450 \mathrm{~nm}$ using a CLARIOstar Plus card reader (BMG Labtech). A cutoff value for the antigen, corresponding to the corrected mean absorbance for samples from 10 blood donors who had had no previous malaria infections, plus three standard deviations.

P. vivax-MSP1 Block 2 haplotype determination from deep sequencing. DNA extraction was performed using the Qiagem genomic DNA extraction kit, and DNA quantification was performed in the spectrophotometer (NanoDrop, Thermo Scientific) and stored at $-20^{\circ} \mathrm{C}$. PCR was based on N-term region amplification of Pv-MSP1 Block 2 using the primers described by Bastos (2007). The reaction was performed at $50 \mathrm{uL}$, in the following concentrations: $1 \mathrm{x}$ buffer; $1.5 \mathrm{mM}$ magnesium chloride; $0.6 \mathrm{pM}$ 
DNTPs; 0.4 pM of each primer, $1 \mathrm{u}$ Taq polymerase enzyme (Invitrogen) and $100 \mathrm{ng}$ DNA. After the reaction, the PCR products were observed in $1.5 \%$ agarose gel and subjected to purification (QIAGEM). The amplicons were stored at $-20^{\circ} \mathrm{C}$ until sequencing.

Preparation of the library and template for high-performance sequencing: The library for the lon Torrent $\mathrm{PGM}^{\mathrm{TM}}$ system was prepared from an equimolar solution of the sets of amplicons generated by the PCR reaction. Each amplicon of $P$. vivax-MSP1Block 2 from the 8 samples had up to $400 \mathrm{bp}$ and were labelled with equimolar inclusion of a multiplex identifier (barcodes) using lon OneTouch ${ }^{\text {TM }}$. At the end of the reaction, a new purification step was performed using the Agencourt ${ }^{\circledR}$ AMPure ${ }^{\circledR}$ XP reagent following the manufacturer's guidelines. Once the preparation of the library was completed, the PCR step was performed in emulsion with microspheres (ion sphere particles - ISP) containing complementary sequences to the adapter P1, using the lon PGM ${ }^{\text {TM }}$ template OT2 200 kit (Cat.4480974-Life Technologies/lon Torrent ${ }^{\text {TM }}$ ) on Ion OneTouch ${ }^{\text {TM }}$ System 2 (Life Technologies) equipment. The ISPs were enriched and placed on a 314 chip, which was placed in the lon $\mathrm{PGM}^{\mathrm{TM}}$ system sequencer, where sequencing took place. The data generated by the PGM were initially analyzed using the Torrent suite 4.2 software installed on the PGM server. Raw sequence reads were separated based on the barcodes from the pooled data into amplicon-specific data, then filtered according to read length, overall quality scores, and presence of primer sequences. Sequences were edited and translated into amino acid sequences using the DNAstar package to identify haplotype sequences located at the beginning of Block 2 (Figure 1).

Statistical methods: Statistical analysis was performed using The GraphPad Prism version 7.04 package. Paired $T$ test was used to compare number of haplotype-specific peptides recognized between primary infection and second episode of pregnant women who had a recurrence (PI+1R group). The repeated measures of one-way ANOVA test were used to compare number of haplotype-specific peptides recognized between primary infection and second and third episodes of pregnant women of more than one recurrences ( $\mathrm{PI}+>2 \mathrm{R}$ group). Differences in IgM and IgG levels were assessed between peptides from haplotypes by one-way nonparametric Kruskal-Wallis test. P-values: ${ }^{* *} p<0.0005$; ${ }^{* *} p<0.005$ and * $p$ $<0.05$.

\section{Results}

\section{Mosaic of P. vivax-MSP1 Block 2 variants}

To assess the magnitude of the diversity of Block 2 around the world, we carried out a search of Genbank sequences of specific quantities of sequences. The alignment of the amino acids of $P$. vivax MSP1 Block 2 sequences found in parasites circulating in Manaus and other endemic regions of Brazil and the world, such as South Korea, Thailand, Bangladesh, Vanuatu, Sri Lanka (Figure 1) shows that Block 2 contains a wide variety of smaller sequences called repetitions that differ in type, number, and position, and which are flanked by semi-conserved sequences (Figure 1). Several semi-conserved sequences upstream and downstream of random repetitions (repeats) helped in the construction of the mosaic, through which we 
are able to distinguish five main allelic families represented by the variants (see below). Six peptides were synthesized from the main semi-conserved sequences (Figure 1).

\section{Antibodies against haplotypic variants of P. vivax MSP1 in malaria recurrences during pregnancy}

The impossibility of using primaquine increases the chance of malaria relapses throughout pregnancy. Seventy-two patients were followed up until delivery and we divided the subjects into three groups: (i): 41 pregnant women presented with only a primary infection (PI) during pregnancy (ONLY_PI); (ii) 17 pregnant women who had an initial infection and a second episode (recurrence) during pregnancy (PI+1R); (iii): 14 pregnant women who had an initial infection, and at least 2 more episodes of malaria during pregnancy $(\mathrm{PI}+>2 \mathrm{R})$. There were no differences in relation to parasitemia (data not shown). In addition, the time of PI was not decisive for risk of recurrences, in the ONLY_PI group the primary infection occurred with a median of 23 weeks $\left(\mathrm{IQ}^{25}=15\right.$ and $\left.\mathrm{IQ}^{75}=30\right)$, while the median of $\mathrm{PI}+1 \mathrm{R}$ and $\mathrm{PI}+>2 \mathrm{R}$ groups were 23 weeks $\left(I^{25} 15\right.$ and $\left.I Q^{75} 29\right)$ and 19 weeks $\left(I Q^{25}=14\right.$ and $\left.I Q^{75}=25\right)$, respectively.

To assess the exposure to different populations of parasites, we evaluated in the successive $\lg M$ and IgG antibodies against 6 variant-specific peptides in the primary malaria, ONLY_PI group (Figure 2A), as well as in the repeated episodes of groups $\mathrm{PI}+1 \mathrm{R}$ and $\mathrm{PI}+>2 \mathrm{R}$ (Figure 2B,C, respectively). Most pregnant women presented IgM that recognized more than one peptide, thus indicating that it was a multiple infection. Of the group ONLY_PI (Figure 2A), 22 (53.7\%) had IgM of more than 1 peptide, $17(41.4 \%)$ presented IgM to 1 peptide, and $2(4.9 \%)$ had no $\operatorname{lgM}$ for peptides of the tested variants. The IgG reactivity was very low, $5(12.2 \%)$ had IgG of more than 1 peptide, $12(29.3 \%)$ presented IgG to 1 peptide, and 24 $(58.5 \%)$ had no lgG for peptides of the tested variants.

Regarding the women of the $\mathrm{PI}+1 \mathrm{R}$ and $\mathrm{PI}+>2 \mathrm{R}$ groups, it was possible to note that the same $\operatorname{lgM}$ antipeptides remained in several women in the successive episodes. Of the group PI+1R (Figure 2B), the sera of 11 pregnant women (64.7\%) presented IgM to more than one peptide and 6 sera (35.3\%) recognized 1 peptide during the first episode. For IgG, the sera of 6 pregnant women $(35.3 .7 \%)$ presented IgG recognized 1 peptide and 11 sera $(67.7 \%)$ had no $\operatorname{lgG}$ for peptides of the tested variants. In the second episode, the sera of 7 (41.2\%) presented IgM that recognized more than 1 peptide, 6 sera (35.3\%) recognized 1 , and 4 sera (23.5\%) recognized no peptides. For IgG, the sera of $1(5.9 \%)$ recognized more than 1 peptide, 5 sera $29.4 \%$ ) recognized 1 peptide, and 12 sera $(70.6 \%)$ recognized no peptides. Interestingly, the mean interval of the second episode of malaria group PI+1R was 8 weeks. The shortest was 5 weeks and the longest was 30 weeks, well above the half-life of IgM in serum (Figure 2B).

In the $\mathrm{PI}+>2 \mathrm{R}$ group, the sera of 10 pregnant women (71.4\%) presented IgM that recognized more than one peptide, 3 sera (21.4\%) recognized only 1 peptide and one serum (7.2\%) had no IgM for peptides of the tested variants in the first episode. For IgG, the sera of 2 pregnant women (14.3\%) recognized more than one peptide, 3 sera (21.4\%) recognized only 1 peptide and 9 sera (64.3\%) had no IgG for peptides of the tested variants. In the second episode, the number of sera with IgM recognizing more than one peptide reduced to 6 (42.9\%), 5 sera (35.7\%) recognized 1 peptide and 3 sera $(21.4 \%)$ did not recognize 
any of the tested. For IgG, one serum (7.1\%) recognized more than one peptide and 13 sera $(92.9 \%)$ did not recognize any of the tested. In the third episode, 6 sera (42.9\%) recognized more than one peptide, 3 sera $(21.4 \%)$ recognized 1 peptide, and 5 sera $(35.7 \%)$ recognized none of the tested peptides. For IgG, 3 sera $(21.4 \%)$ recognized more than one peptide and 11 sera $(78.6 \%)$ did not recognize any of the tested. Some pregnant women still had fourth and fifth episodes and showed the same trend. The mean intervals were 7.5 weeks from the primary infection until the 2 second episode, 5 weeks for the third episode, and 4 weeks for those who had a fourth episode, while the range of intervals varied between 4 weeks and 11 weeks (Figure 2C).

Regarding the IgM to IgG switch, 6 women in the ONLY_PI group presented the IgM to IgG switch, 5 in the $\mathrm{PI}+1 \mathrm{R}$ group showed the switch in the first infection and only 1 showed the switch in the second episode. Regarding $\mathrm{PI}+>2 \mathrm{R}$ group, 4 showed the switch in the first infection, 1 showed it in the second episode, 2 showed it in the third episode and 1 showed it in the fourth episode. In the primary infection, no differences were observed in relation to the number of peptides recognized by sera of three groups of pregnant women (Figure 3). The number of peptides recognized by IgM in sera of pregnant women of $\mathrm{PI}+1 \mathrm{R}$ group showed a trend towards a reduction between the primary infection and the second malaria episode. With sera of pregnant women of the $\mathrm{PI}+>2 \mathrm{R}$ group, the number of peptides recognized by $\operatorname{lgM}$ in the primary infection in relation to second and third malaria episodes reduced significantly $(p=0.012)$. This reduction was also observed with IgG among the pregnant women of the PI+>2R group (Figure 3 ).

\section{IgM anti-peptides as a tool for monitoring reexposure to P. vivax MSP1 Block 2 haplotypes}

In relation to the pregnant women in $\mathrm{PI}+>2 \mathrm{R}$ group, the shortest period between the first and second episodes was 2 weeks and the longest 13 weeks. Between the second and third episodes, one week was the shortest period and eleven weeks was the longest. It is worth highlighting patient S-60 of this group, for whom the period between the two episodes was the shortest at only 2 weeks. In the first episode this woman had IgM that recognized five peptides and in the second episode this reduced to 3 peptides (Figure $2 \mathrm{C}$ ). It can be seen in most of the pregnant women of $\mathrm{PI}+1 \mathrm{R}$ and $\mathrm{PI}+>2 \mathrm{R}$ groups that some peptides recognized in one episode seroconverted negatively in the subsequent episode (Figures 2B,C). Thus, the presence of $\operatorname{lgM}$ in successive episodes in both PI+1R and PI+>2R groups most likely indicates re-exposure to the same haplotype of MSP1 Block 2.

This assumption is better verified when IgM antibody levels against each peptide are followed throughout the relapses (Figures 4 and 5). Regarding the PI+1R group, for each peptide, it was possible to verify the maintenance of IgM levels or even the increase in the second episode in relation to the initial infection. Subject S-47 had her second episode 5 weeks after the primary infection, the second episode of subject S-50 was 21 weeks after the primary infection and S-53 had her second episode 11 weeks after. They all maintained or increased IgM levels against peptide 1 in episode 2 (Figure 4A). The subject S-44 had her second episode 15 weeks after the primary infection and subject S-48 had hers 6 weeks after, and they all presented increases in IgM levels against peptide 2 (Figure 4B). Subject S- 55 had her second episode six weeks later and increased IgM against peptide 3 as did subjects S-44, S-48 and S-50 (Figure 4C). The 
same was observed with subjects S-56 and S-57 in relation to peptide 4 and the period between the primary infection and the second episode was 18 and 14 weeks, respectively (Figure 4D). Subjects S-44, S-47 and S-48 had increases in IgM against peptides 5 and 6 (Figures 4E and F).

These observations were most evident in PI+>2R group. Subjects S-61, S-64 and S-69 showed maintenance of IgM levels against peptide 1 between the second and third episodes and the interval between these was from four to seven weeks, which was enough time to reduce IgM levels if there was no re-exposure to the same haplotype (Figure $5 \mathrm{~A}$ ). This behavior of maintenance or an increase in the following episode happened with other peptides. Subjects S-60, S-62 and S-69, and peptide 2 (Figure 5B), S-59, S-61, S-62, S-64, S-69, and S-71 and peptide 3 (Figure 5C), S-62, S-68 and S-69 and peptide 4 (Figure 5D), S-61, S-62, S-65, and S-69 and peptide 5 (Figure 5E), and the S-64, S-65, and S- 69 and peptide 6 (Figure 5F) should be highlighted. Some pregnant women had serial increases in IgM against some peptides in more than two episodes, S-51 and the haplotype of peptide 2 for four episodes (Figure 5B), S53 and the haplotype of the peptide 3 (Figure 5C), S-51, S-53, S-58, and S-61 and the haplotype of peptide 4 (Figure 5D). The maintenance of, or even increase in, IgM levels throughout the pregnancy probably indicates the re-exposure to the same populations of $P$. vivax MSP1 Block 2 haplotypes.

\section{Amplicon Deep Sequencing (ADS) and haplotype-specific serology as a new tool for distinguishing between reinfections and relapses in malaria}

Serology based on the haplotype-specific peptides of Block 2 indicated multiclonal infections in pregnant women infected with malaria, but also variations in specific IgM levels. ADS is highly sensitive and allows the detection of an overlap in a mixture of sequences obtained in the PCR reaction. To detect the existence of multiclonal infections, we performed the ADS technique in eight samples of patients infected with P. vivax to determine if infections were by one or more haplotypes. Two samples (PV04 and PV08) were from prime-infected individuals, and ADS indicated infection by only 1 haplotype and the same DENAKR haplotype......NNAAQGSTGNTETGTQSSA, in $100 \%$ of the reads. This haplotype corresponds to the peptide sequence of Block 2 of the Belem strain of $P$. vivax [38]. We evaluated the IgM and IgG responses using a new panel of overlapped peptides and mapped the sequences of the main haplotypes found in the Manaus region, called overlapped, specific, P. vivax-Block 2 haplotype peptides (Figure 6A) [21]. Among eight samples used in ADS, two were of prime-infected malaria patients. The reactivity of IgM was observed for the peptides of the same haplotype detected in ADS only (arrows, Figure 6B), while for IgG, no reactivity was observed for any of the peptides of the same haplotype or the others.

The six remaining samples were from individuals who already had a history of malaria, ADS showed infection by a haplotype in three of them (PV02, PV03 and PV05). In two cases (PV02 and PV05) the Belem haplotype was detected and, in PV03, the DENARKG haplotype...DMING........DENY was identified (Figure $6 \mathrm{C}$ ). Once more, a reactivity of IgM was observed only for the peptides of the same haplotype detected by ADS (arrows Figure 6C). Serology showed a trend towards an increase in IgG levels against the peptides of the other haplotypes in relation to the peptides of the haplotype of the current infection, whereas these patients have already had previous malaria episodes (Figure 6C). This lack of reactivity is 
consistent with the humoral response against polymorphic antigens in the first days of the acute phase of malaria from a first contact, as found by other authors who used recombinant proteins of similar haplotypes [39].

Samples PV01, PV06 and PV07 were infected by three haplotypes each. All had a history of 4 other previous episodes of malaria. The ADS allowed the quantification of these haplotypes and in all the samples there was a predominant haplotype with more than $95 \%$ of the reads (Figure 7). Sample PV01 was infected with the haplotypes AENK, DENARKG...DMING........DENY and Belem in descending order. Sample PV06 was infected with DENARKG haplotypes.....TTNTGT.......VSG (2), DENARKG...DMING........DENY DENARKG.....TTNTGT.......VSG in descending order of read sequences. In sample PV07, haplotype AENK, followed Belem and DENARKG...DMING ........DENY (Figure 7A).

In this case, the serology was performed only with overlapped, specific, P. vivax-Block 2 haplotype peptides detected by ADS (Figure 7A). IgM levels were different between haplotypes detected by ADS, their levels were similar to those $P$. vivax-Block 2 peptides of haplotypes quantified in ADS (Figure 7B). In relation to IgG, there was a trend towards IgG levels being lower against the overlapping peptides corresponding to the predominant haplotypes (Figure 7C). In the PV07 isolate, which presented the AENKKRSGHPTTTTNGAGTQPANGSIA haplotype with $97.6 \%$ of the reads, the lgG levels against the predominant haplotype AENKKRSGHPTTTTNGAGTQPANGSIA was lower than the antibody levels against the Belem haplotype, which was the second most frequent, but with a lower number of reads in the order of two logs. This inconsistency between levels of specific antibodies against the Belem haplotype and the parasite load estimated by the number of reads shows the importance of the combination of these two methodologies in the study of the biology of malaria caused by P. vivax.

\section{Discussion}

Relapses are due to persistent stages of the parasite in the liver (hypnozoites) and are important causes of morbidity in $P$. vivax infections [1]. These can only be prevented by the antimalarial 8-aminoquinoline; however, due to uncertainty about the risks of induced hemolysis in individuals with G6PD deficiency, such as the fetus in pregnant women, they are not administered, and malaria during pregnancy is associated with a wide spectrum of clinical manifestations [31, 33-35, 35, 40-42]. From the serology of a panel of peptides generated from the main haplotypes of $P$. vivax MSP1 Block 2, we were able to show the re-exposure to the same parasite populations in pregnant women that had successive malaria episodes. As such, by combining haplotype-specific Block 2 serology with deep sequencing of the MSP1 Block 2 PCR product, we developed a strategy that enables the evaluation of relapses in malaria by $P$. vivax.

Susceptibility to malaria associated with pregnancy occurs though combination of immune and hormonal changes along with the presence of infections by multiple genotypes of parasites co-infecting a single host $[32,40]$. This can be the result of independent bites of infected mosquitoes or a single mosquito containing populations of genetically diverse sporozoites [43]. Herein, the serology was able to 
demonstrate a multiplicity of infections through of presence of IgM for different haplotype-specific peptides in the primary infection of pregnant women who had successive episodes, as well as in those who had only one infection throughout pregnancy. Moreover, the amount of IgM anti-haplotype-specific peptides in the initial infection in the three groups of pregnant women showed no difference (Figure 3). Therefore, the multiclonal infections and time of primary infection were not the reason for successive recurrences in the pregnant women of the $\mathrm{PI}+1 \mathrm{R}$ and $\mathrm{PI}+>2 \mathrm{R}$ groups in relation to those who had only the primary infection.

White's mechanism for relapse activation of $P$. vivax in a malaria endemic area indicates that there is one hypnozoite of each genotype, and the syndrome caused by infection in the blood stage activates other hypnozoites, and that relapses continue until the number of hypnozoites runs out or some cease to be activated [1]. In our study, we identified a significant reduction in the number of peptides recognized throughout the relapses in the $\mathrm{PI}+>2 \mathrm{R}$ group of pregnant women, as well as a trend in the group of only one relapse (Figure 3), which would be in accordance with the depletion of the contingent of hypnozoites throughout the relapses [1].

Relapses are derived from parasites that are either genetically similar or different from the initial infection, which indicates that some derive from previous infections [12]. Usually, P. vivax relapses are identified by microsatellite markers or molecular methods such as restriction fragment length polymorphism and amplicon sequencing $[2,13,32,43]$ Our major limitation in the study was that we did not use a genotyping method to confirm the relapses [5]. Nonetheless, we were able to show the reexposure to the same haplotypes in successive episodes that happened in short intervals. Some haplotypes were maintained or had increased IgM levels, indicating exposure to the same parasite populations (Figures 4 and 5). Thus, the IgM serology with our panel of peptides generated from the main haplotypes of $P$. vivax MSP1 Block 2 may be a tool for studies of the population structure of $P$. vivax.

Block 2 presents a great diversity of semi-conserved sequences and repeats, (Figure 1). We used ADS to quantify the mixtures of amplicons based on $P$. vivax Block 2 haplotypes, which are unlikely to happen by chance as single-based polymorphisms $[5,43]$. Of the eight samples from adult patients with malaria, five samples had infections by one only haplotype of Block 2, two of them were prime-infected patients and others 3 have already had previous malaria. The serology with the panel of overlapping peptides of each haplotype showed higher IgM levels against the corresponding haplotype detected in the NGS as well prime-infected as malaria exposed patients. In contrast, the corresponding haplotype detected in the NGS were not well recognized by IgG antibodies. The most important finding was that among others three samples from adult patients with malaria, infections by different haplotypes of Block 2 were observed in 3 of them and they had had previous episodes of malaria. In all three, the almost absolute predominance of more than $95 \%$ of one of the haplotypes in the readings was observed. Moreover, IgG levels compared with a panel of overlapping peptides of each haplotype showed no correlation with the parasitic load corresponding to the "reads" in the NGS. Interestingly, in the sample PV07, IgG levels were higher with the peptides of one of the minority haplotypes. These findings are similar to White's mechanism of P. vivax hypnozoite activation, which proposes when a pre-erythrocytic schizont from a newly inoculated

Page $11 / 23$ 
sporozoite reaches pyrogenic densities, it activates previously acquired hypnozoites to initiate bloodstage infection. However, the consequent febrile illness caused by the newly inoculated population suppresses the multiplication of blood stages originating from those reactivated hypnozoites [1]. We cannot confirm this because only the collection in the current infection was analyzed. Nonetheless, our data show a proof of concept that the combination of deep sequencing of Block 2 amplicons of MSP1 and a panel serology of peptides corresponding to the same haplotypes may be a promising tool for relapse studies in vivax malaria.

The study has other limitations, such as the number of haplotype-specific peptides. We elaborated six peptides, but it is possible to do more to increase the repertoire of haplotypic variants. We used only eight peripheral blood samples to perform the ADS methodology in NGS. Another limitation is that the patients responded that they had received antimalarial therapy for the previous episode but did not know the exact primaquine doses.

In conclusion, so far, preliminary analysis suggests that serology based on PvMSP1 Block 2 haplotypes may be a useful system for observing the response against a specific haplotype. The use of this deep sequencing methodology of $P$. vivax MSP1 Block 2 amplicons allows the identification of multiclonal infections based on PvMSP1 Block 2 haplotypes. Therefore, the combination of haplotype genotyping and haplotype-specific serology makes it possible to understand the dynamics of exposure to $P$. vivax parasites. Although still preliminary, the data indicate that this system can serve as a sentinel tool for investigation of hypnozoite reactivation.

\section{Declarations}

\section{Ethics approval}

Samples of Plasmodium vivax infected pregnant women were obtained from BioBank from Departmento de Parasitologia, Instituto Ciencias Biomedicas, Universidade de São Paulo, (Biorrep_CEPUSP) under approbation of Ethical approval was provided by the Universidade de São Paulo Ethics Review Board (CAAE 50158321.0.0000.5467). Samples of eight Plasmodium vivax-infected adults were obtained of Biobank of Instituto Leonidas e Maria Deane (Fiocruz-Amazonas) and approved by the Fundação de Medicina Tropical Dr. Heitor Vieira Dourado Ethics Review Board (CAAE: 42021515.0.3001.0005).

\section{Availability of data and materials}

The datasets of the current study can be available from the corresponding author on reasonable request.

\section{Consent for publication}

The authors declare that they have no competing interests

\section{Funding}


This work was supported by grants from the Programa de Excelência em Pesquisa do Instituto Leônidas e Maria Deane, 2016-2017 (FIOCRUZ AMAZONIA). EF received a post-doctoral fellowship from FIOCRUZ AMAZONIA. RAA, FGN and PAN are level II CNPq fellows.

\section{Authors' contributions}

Author Contributions: PAN had full access to all of the data in the study and takes responsibility for the integrity of the data and the accuracy of the data analysis. Concept and design: EF and PAN. Serology EF, Design and Peptide synthesis RAA, MIF and PF; Amplicon deep sequencing (extraction, acquisition and analysis) EF, VS and FGN: All authors. Drafting of the manuscript: EF, PAN. Critical revision of the manuscript for important intellectual content: All authors.

\section{Authors' information}

Not applicable.

\section{Acknowledgements}

We thank to Professor Claudio Romero Farias Marinho, PhD; Jamille Dombrowski, PhD (both of Department of Parasitology, Institute of Biomedical Sciences, University of São Paulo, São Paulo, Brazil) and Rodrigo Medeiros de Souza, PhD (Multidisciplinary Center, Federal University of Acre, Acre, Brazil) by supplying the samples of Plasmodium vivax-infected pregnant women and by the critical revision of the manuscript.

\section{References}

1. White NJ. Determinants of relapse periodicity in Plasmodium vivax malaria. Malar J. 2011;10 October.

2. Craig AA, Kain KC. Molecular analysis of strains of Plasmodium vivax from paired primary and relapse infections. J Infect Dis. 1996;174:373-9.

3. Battle KE, Karhunen MS, Bhatt S, Gething PW, Howes RE, Golding N, et al. Geographical variation in Plasmodium vivax relapse. Malar J. 2014;13:144. doi:10.1186/1475-2875-13-144.

4. Chu CS, White NJ. Management of relapsing Plasmodium vivax malaria. Expert Rev Anti Infect Ther. 2016;14:885-900.

5. Lin JT, Hathaway NJ, Saunders DL, Lon C, Balasubramanian S, Kharabora O, et al. Using Amplicon Deep Sequencing to Detect Genetic Signatures of Plasmodium vivax Relapse. J Infect Dis. 2015;212:999-1008.

6. Rezende AM, Tarazona-Santos E, Fontes CJF, Souza JM, Couto ADA, Carvalho LH, et al. Microsatellite loci: Determining the genetic variability of Plasmodium vivax. Trop Med Int Heal. 2010;15:718-26. 
7. Thanapongpichat S, McGready R, Luxemburger C, Day NP, White NJ, Nosten F, et al. Microsatellite genotyping of Plasmodium vivax infections and their relapses in pregnant and non-pregnant patients on the Thai-Myanmar border. Malar J. 2013;12:1. doi:10.1186/1475-2875-12-275.

8. Shelke, A. R., Roscoe, J. A., Morrow, G. R., Colman, L. K., Banerjee, T. K., \& Kirshner JJ. Identification of a Polymorphic Plasmodium Vivax Microsatellite Marker. Bone. 2008;23:1-7.

9. Lin JT, Hathaway NJ, Saunders DL, Lon C, Balasubramanian S, Kharabora O, et al. Using Amplicon Deep Sequencing to Detect Genetic Signatures of Plasmodium vivax Relapse. J Infect Dis. 2015;212:999-1008.

10. Nkhoma SC, Nair S, Cheeseman IH, Rohr-Allegrini C, Singlam S, Nosten F, et al. Close kinship within multiple-genotype malaria parasite infections. Proc R Soc B Biol Sci. 2012;279:2589-98.

11. Chen N, Auliff A, Rieckmann K, Gatton M, Cheng Q. Relapses of Plasmodium vivax Infection Result from Clonal Hypnozoites Activated at Predetermined Intervals. J Infect Dis. 2007;195:934-41.

12. Restrepo E, Imwong M, Rojas W, Carmona-Fonseca J, Maestre A. High genetic polymorphism of relapsing P. vivax isolates in northwest Colombia. Acta Trop. 2011;119:23-9.

13. de Araujo FCF, de Rezende AM, Fontes CJF, Carvalho LH, Alves de Brito CF. Multiple-Clone Activation of Hypnozoites Is the Leading Cause of Relapse in Plasmodium vivax Infection. PLoS One. 2012;7:1-9.

14. del Portillo H, Longacre S, Khouri E, David P. Primary structure of the merozoite surface antigen 1 of Plasmodium vivax reveals sequences conserved between different Plasmodium species. Proc Natl Acad Sci U S A. 1991;88:4030-4.

15. Ferreira MU, Liu Q, Kaneko O, Kimura M, Tanabe K, Kimura EAS, et al. Allelic diversity at the merozoite surface protein-1 locus of Plasmodium falciparum in clinical isolates from the southwestern Brazilian Amazon. Am J Trop Med Hyg. 1998;59:474-80.

16. Conway DJ, Cavanagh DR, Tanabe K, Roper C, Mikes ZS, Sakihama N, et al. A principal target of human immunity to malaria identified by molecular population genetic and immunological analyses. Nat Med. 2000;6:689-92.

17. Bharti PK, Shukla MM, Sharma YD, Singh N. Genetic diversity in the block 2 region of the merozoite surface protein-1 of Plasmodium falciparum in central India. Malar J. 2012;11:78. doi:10.1186/14752875-11-78.

18. Putaporntip C, Jongwutiwes S, Sakihama N, Ferreira MU, Kho W-G, Kaneko A, et al. Mosaic organization and heterogeneity in frequency of allelic recombination of the Plasmodium vivax merozoite surface protein-1 locus. Proc Natl Acad Sci U S A. 2002;99:16348-53.

19. Takala SL, Coulibaly D, Thera M a, Batchelor AH, Cummings MP, Escalante A a, et al. Malaria: Implications for Vaccine Development. Sci Transl Med. 2009;1:1-21.

20. Beeson JG, Drew DR, Boyle MJ, Feng G, Fowkes FJI, Richards JS. Merozoite surface proteins in red blood cell invasion, immunity and vaccines against malaria. FEMS Microbiol Rev. 2016; January:fuw001. doi:10.1093/femsre/fuw001. 
21. Soares LA, Evangelista J, Orlandi PP, Almeida ME, Sousa LP De, Chaves Y, et al. Genetic diversity of MSP1 Block 2 of plasmodium vivax isolates from manaus (Central Brazilian Amazon). J Immunol Res. 2014;2014:14-6.

22. Versiani FG, Almeida MEM, Melo GC, Versiani FOL, Orlandi PP, Mariúba LAM, et al. High levels of IgG3 anti ICB2-5 in Plasmodium vivax-infected individuals who did not develop symptoms. Malar J. 2013;12:294. doi:10.1186/1475-2875-12-294.

23. Versiani FG, Almeida ME, Mariuba LA, Orlandi PP, Nogueira PA. N-terminal Plasmodium vivax merozoite surface protein-1, a potential subunit for malaria vivax vaccine. Clin Dev Immunol. 2013;2013:965841. doi:10.1155/2013/965841.

24. Nogueira P, Alves F, Fernandez-Becerra C, Pein O, Santos N, Pereira da Silva L, et al. A reduced risk of infection with Plasmodium vivax and clinical protection against malaria are associated with antibodies against the $\mathrm{N}$ terminus but not the $\mathrm{C}$ terminus of merozoite surface protein 1 . Infect Immun. 2006;74:2726-33.

25. Tetteh KKA, Cavanagh DR, Corran P, Musonda R, McBride JS, Conway DJ. Extensive antigenic polymorphism within the repeat sequence of the Plasmodium falciparum merozoite surface protein 1 block 2 is incorporated in a minimal polyvalent immunogen. Infect Immun. 2005;73:5928-35.

26. Tetteh KK a, Conway DJ. A polyvalent hybrid protein elicits antibodies against the diverse allelic types of block 2 in Plasmodium falciparum merozoite surface protein 1. Vaccine. 2011;29:7811-7. doi:10.1016/j.vaccine.2011.07.106.

27. Cutts JC, Powell R, Agius P a, Beeson JG, Simpson J a, Fowkes FJI. Immunological markers of Plasmodium vivax exposure and immunity: a systematic review and meta-analysis. BMC Med. 2014;12:150. doi:10.1186/s12916-014-0150-1.

28. Cavanagh D, Dodoo D, Hviid L, Jørgen A, Theander T, Akanmori B, et al. Antibodies to the N-Terminal Block 2 of Plasmodium falciparum Merozoite Surface Protein 1 Are Associated with Protection against Clinical Malaria Antibodies to the $\mathrm{N}$-Terminal Block 2 of Plasmodium falciparum Merozoite Surface Protein 1 Are Associated with. 2004;72:6492-502.

29. Cavanagh D, Elhassan I, Roper C, Robinson V, Giha H, Holder A, et al. A longitudinal study of typespecific antibody responses to Plasmodium falciparum merozoite surface protein-1 in an area of unstable malaria in Sudan. J Immunol. 1998;161:347-59.

30. Pincelli A, Neves PAR, Lourenço BH, Corder RM, Malta MB, Sampaio-Silva J, et al. The Hidden Burden of Plasmodium vivax Malaria in Pregnancy in the Amazon: An Observational Study in Northwestern Brazil. Am J Trop Med Hyg. 2018;99:73-83.

31. Brummaier T, Gilder ME, Gornsawun G, Chu CS, Bancone G, Pimanpanarak M, et al. Vivax malaria in pregnancy and lactation: A long way to health equity. Malar J. 2020;19:1-7. doi:10.1186/s12936020-3123-1.

32. Lopez-Perez M, Pacheco MA, Buriticá L, Escalante AA, Herrera S, Arévalo-Herrera M. Malaria in pregnancy: A passive surveillance study of pregnant women in low transmission areas of Colombia, Latin America. Malar J. 2016;15:1-10. 
33. Ataíde R, Murillo O, Dombrowski JG, Souza RM, Lima FA, Lima GFMC, et al. Malaria in Pregnancy Interacts with and Alters the Angiogenic Profiles of the Placenta. PLoS Negl Trop Dis. 2015;9:e0003824. doi:10.1371/journal.pntd.0003824.

34. Dombrowski JG, Barateiro A, Peixoto EPM, Barros ABC da S, de Souza RM, Clark TG, et al. Adverse pregnancy outcomes are associated with plasmodium vivax malaria in a prospective cohort of women from the brazilian amazon. PLoS Negl Trop Dis. 2021;15:1-23.

35. Dombrowski JG, De Souza RM, Lima FA, Bandeira CL, Murillo O, De Sousa Costa D, et al. Association of malaria infection during pregnancy with head circumference of newborns in the brazilian amazon. JAMA Netw Open. 2019;2.

36. Ferreira M, Castro M. Challenges for malaria elimination in Brazil. Malar J. 2016;15:1-18.

37. Kohara-Melchior, LA Chiaravalloti-Neto F. Spatial and spatio-temporal analysis of malaria in the state of Acre, western Amazon, Brazil. Geospat Heal. 2016;11.

38. Valderrama-Aguirre A, Quintero G, Gómez A, Castellanos A, Pérez Y, Méndez F, et al. Antigenicity, immunogenicity, and protective efficacy of Plasmodium vivax MSP1 Pv200L: A potential malaria vaccine subunit. Am J Trop Med Hyg. 2005;73 5 SUPPL.:16-24.

39. Bastos MS, Da Silva-Nunes M, Malafronte RS, Hoffmann EHE, Wunderlich G, Moraes SL, et al. Antigenic polymorphism and naturally acquired antibodies to Plasmodium vivax merozoite surface protein 1 in rural Amazonians. Clin Vaccine Immunol. 2007;14:1249-59.

40. Rogerson SJ, Hviid L, Duffy PE, Leke RF, Taylor DW. Malaria in pregnancy: pathogenesis and immunity. Lancet Infect Dis. 2007;7:105-17.

41. Nosten F, McGready R, Simpson JA, Thwai KL, Balkan S, Cho T, et al. Effects of Plasmodium vivax malaria in pregnancy. Lancet. 1999;354:546-9.

42. Souza RM, Ata??de R, Dombrowski JG, Ipp??lito V, Aitken EH, Valle SN, et al. Placental Histopathological Changes Associated with Plasmodium vivax Infection during Pregnancy. PLoS Negl Trop Dis. 2013;7:1-11.

43. Zhong D, Koepfli C, Cui L, Yan G. Molecular approaches to determine the multiplicity of Plasmodium infections. Malar J. 2018;17:1-9. doi:10.1186/s12936-018-2322-5.

\section{Figures}




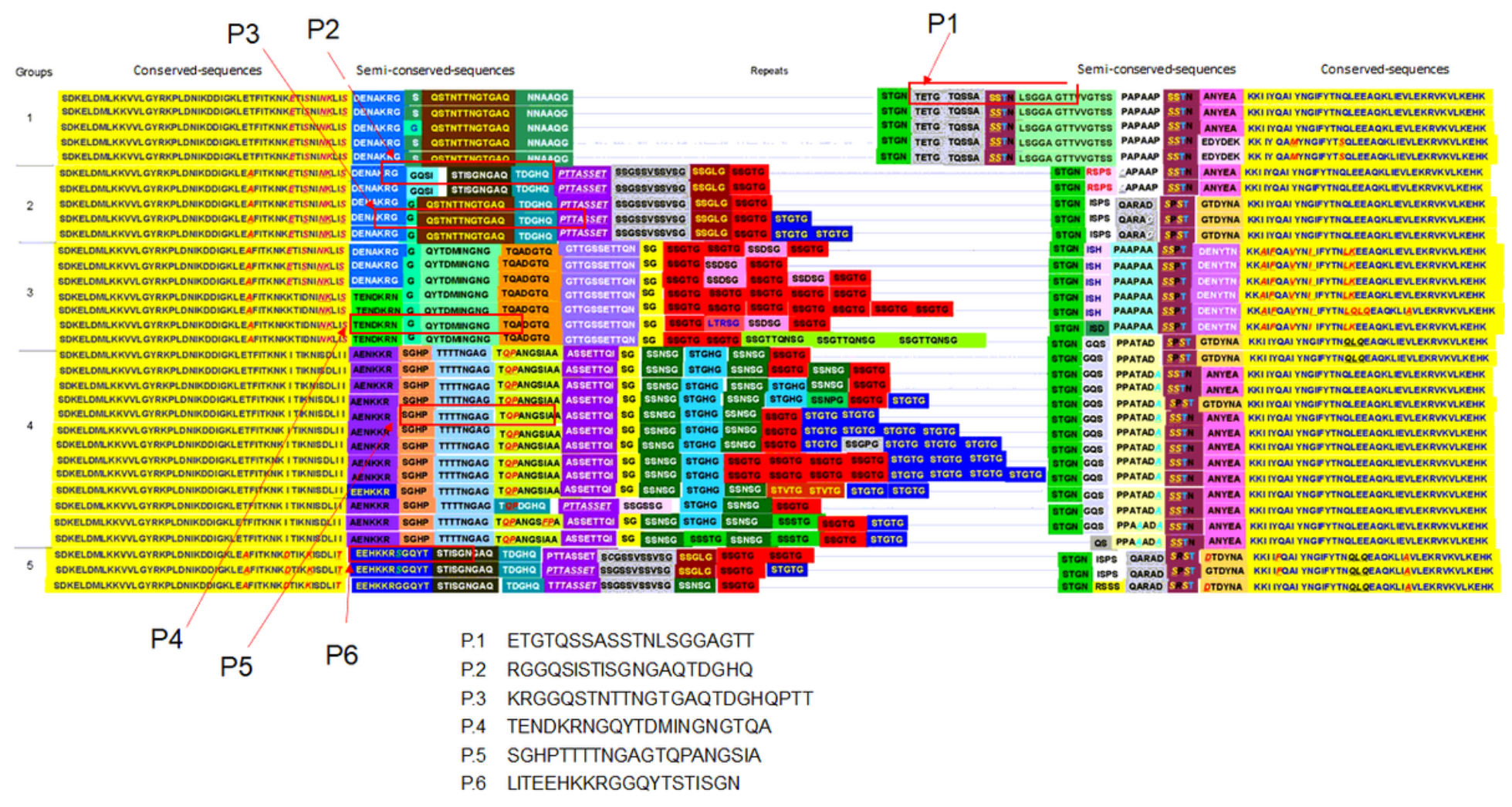

Figure 1

Exploration of PvMSP1 Block 2 genetic diversity. A) A mosaic assembly of several Block 2 sequences obtained from the GenBank database containing hybrid (or semi-conserved series) flanking random repeats. The mosaic was drawn using different colors for the conserved, hybrid and repeat sequences to facilitate comprehension of diversity. Five allelic families sharing hybrid sequences up- and downstream of random repeats. B) A panel of six allelic variant peptides derived from containing major semiconserved sequences upstream of repeats was constructed (P1, P2, P3, P4, P5 and P6). 
A

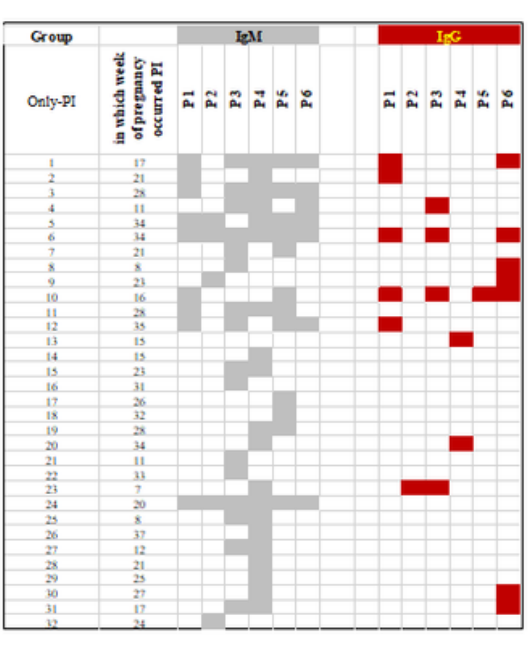

B

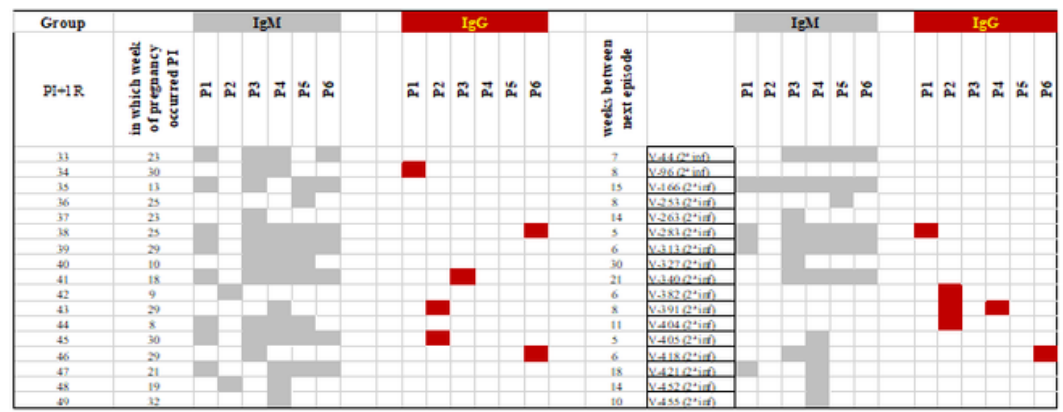

C

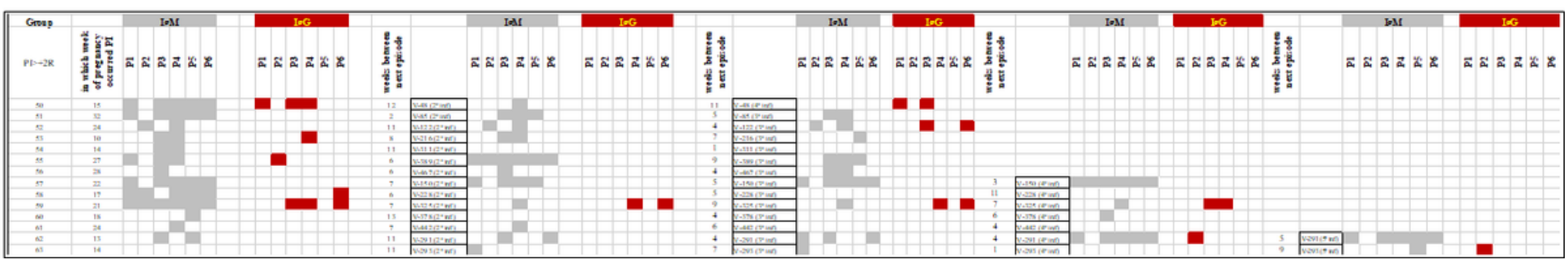

Figure 2

Distribution of the lgM and IgG reactivity from serum of pregnant women with vivax malaria divided into groups. A) women who have had only a single malaria infection during pregnancy. B) women who had an infection and a relapse of malaria (1-Inf+1R). C) women who had an infection and 2 to 4 relapses (1Inf+>2R). Each line represents a pregnant woman. Peptides P1 to P6 were developed against variant sequences of six Block 2 haplotypes of $P$. vivax MSP1 (merozoite surface protein-1). White square negatives. Gray square - serums with IgM reactivity against respective peptides in which they appeared only once at some point during pregnancy. Red square - serums with IgG reactivity. 
A

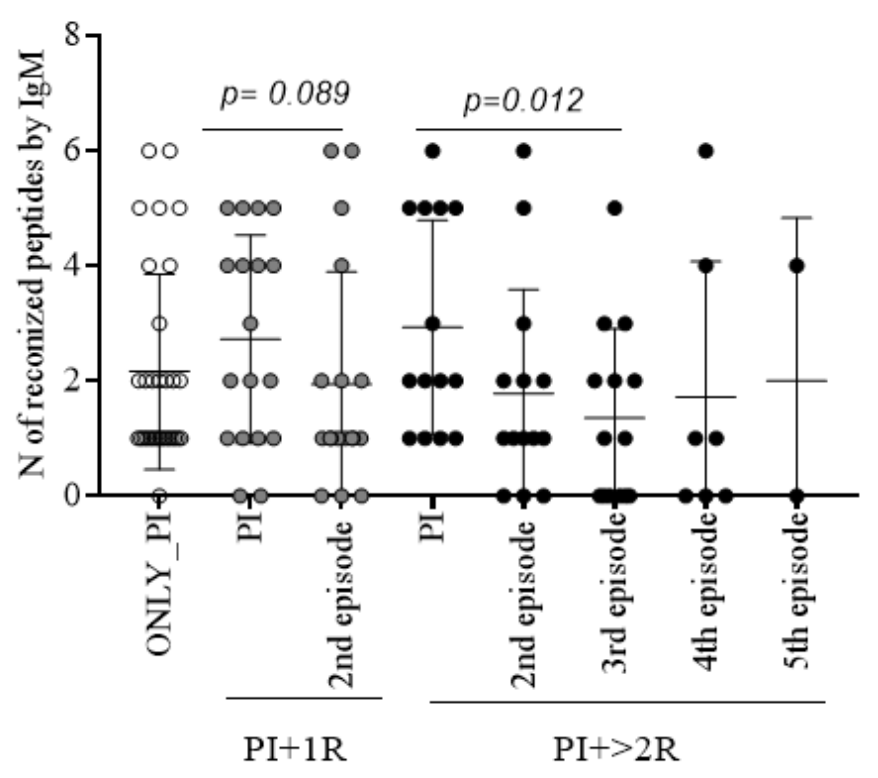

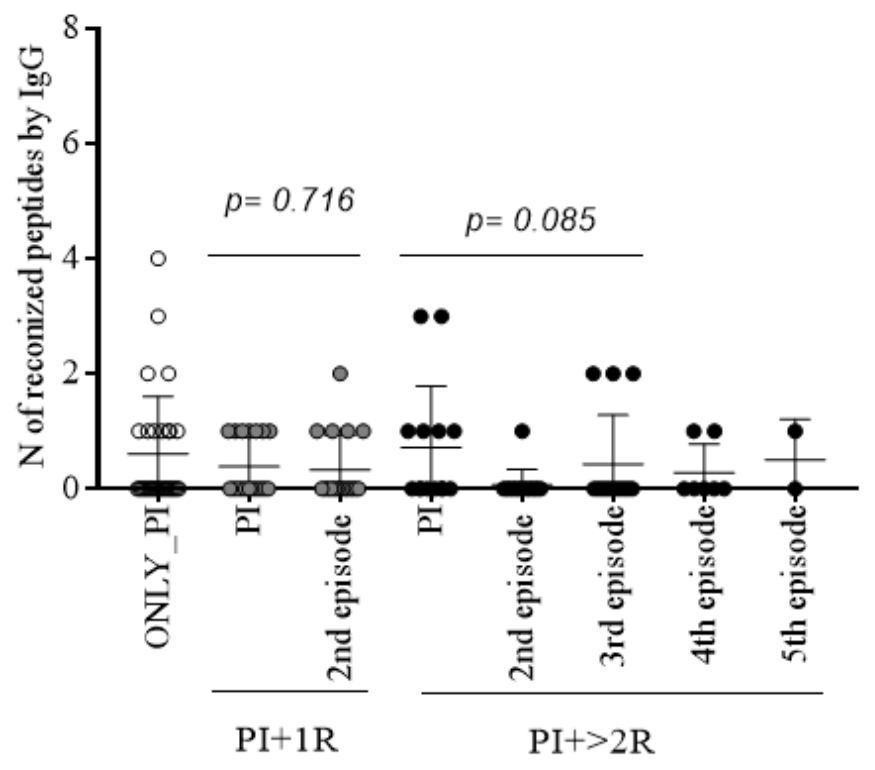

Figure 3

Comparison of the number of haplotype-specific peptides recognized. Number of peptides recognized through IgM (A) and IgG (B) in 41 women in the Only_1_inf group (who only had a malaria episode during pregnancy), 17 in the 1-PI+1R group (had an initial infection and a relapse) and 14 in the $\mathrm{PI}+>2 \mathrm{R}$ group (had an initial infection and two more relapse episodes in the second and third trimester). Paired $\mathrm{T}$ test was used to compare number of haplotype-specific peptides recognized between primary infection and second episode of pregnant women of PI+1R group. The repeated measures of one-way ANOVA test were used to compare number of haplotype-specific peptides recognized between primary infection and second and third episodes of pregnant women of $\mathrm{PI}+>2 \mathrm{R}$ group. 
A

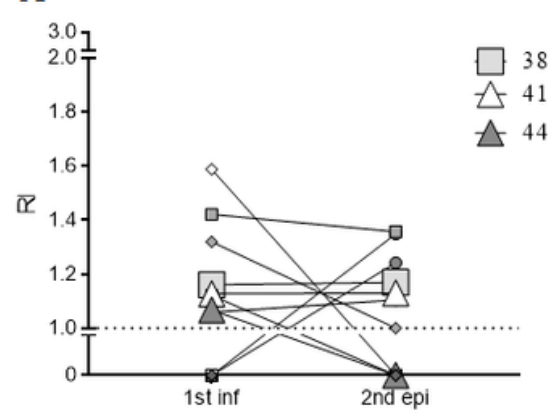

$\mathrm{D}$

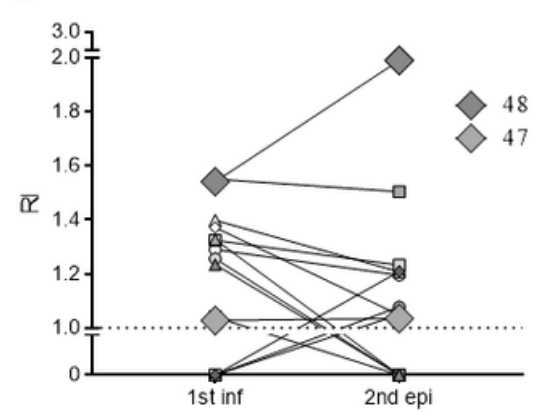

B

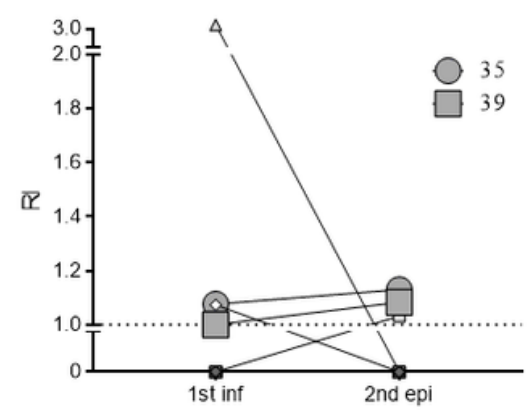

P5

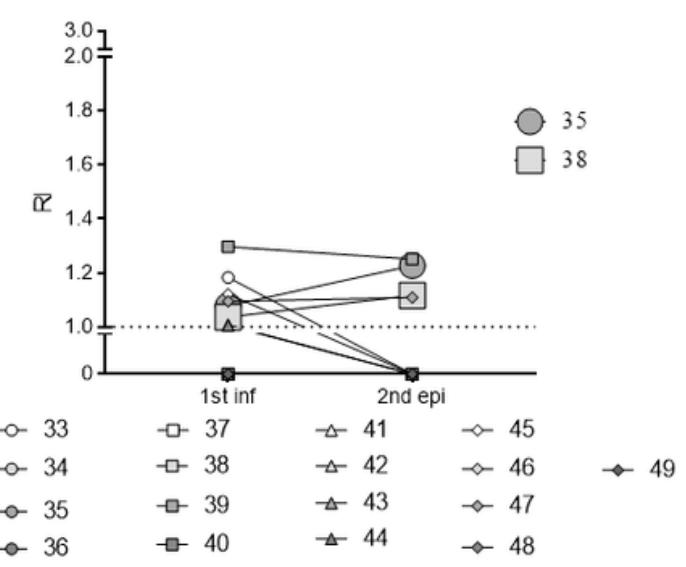

$\mathrm{C}$

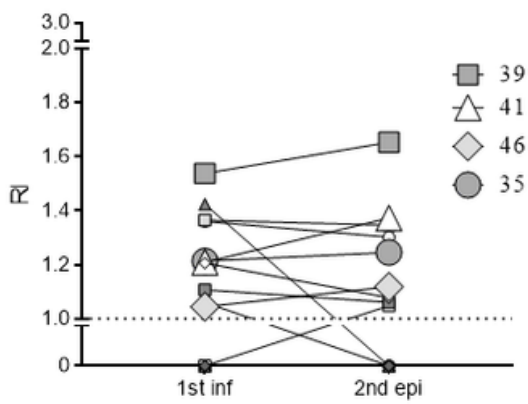

F

P6

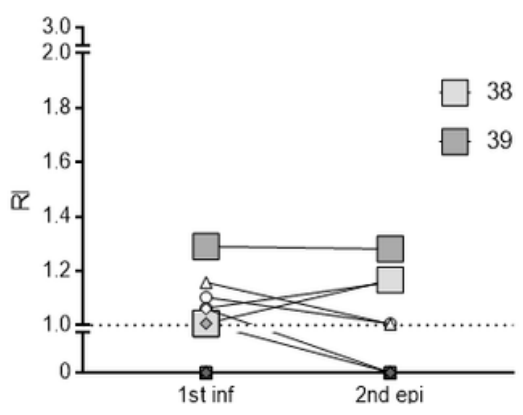

Figure 4

Serology of P.vivax-MSP1 Block 2 specific haplotype peptides of pregnant women who have had a primary infection and a second malaria episode. Of the women, 17 had an initial infection and a relapse, which were confirmed by microscopy of the thick and thin smears of peripheral blood and PCR. Serology for IgM was performed against 6 haplotype-specific peptides of $P$. vivax MSP1 Block 2 A) P1, B) P2, C) P3, D) P4, E) P5 and F) P6. Dashed lines positivity in relation to cutoff values for each peptide calculated by mean absorbance for samples from 10 blood donors who had had no previous malaria infections, plus three standard deviations. Each woman was represented by a symbol (see below). Those women who maintained or increased IgM levels on relapse relative to the initial infection, their respective symbols have been increased and showed to the right of each graph. 


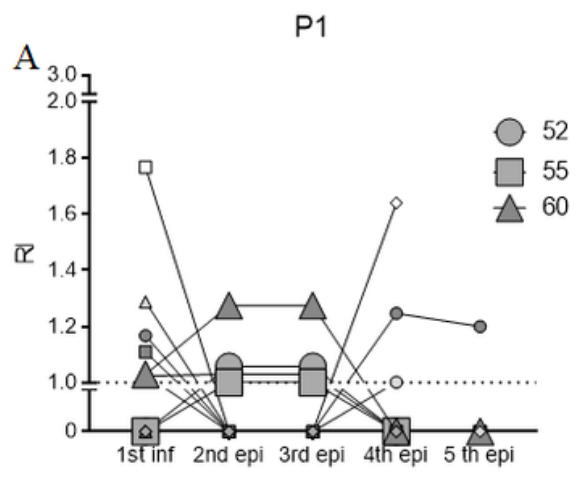

P4

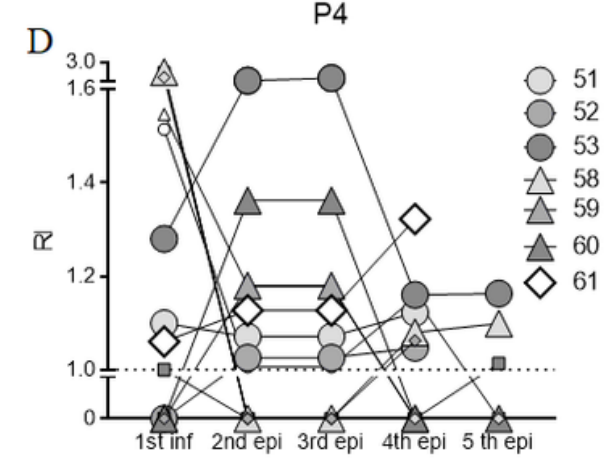

B

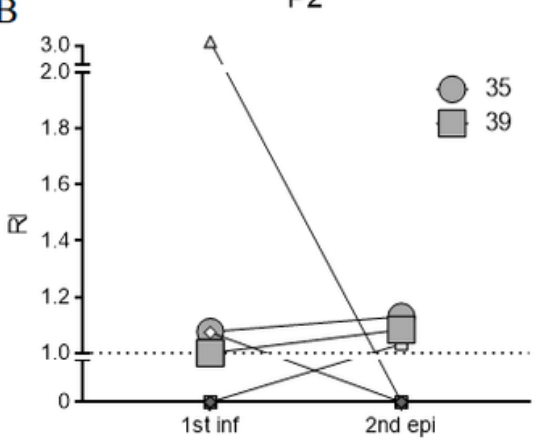

$\mathrm{E}$

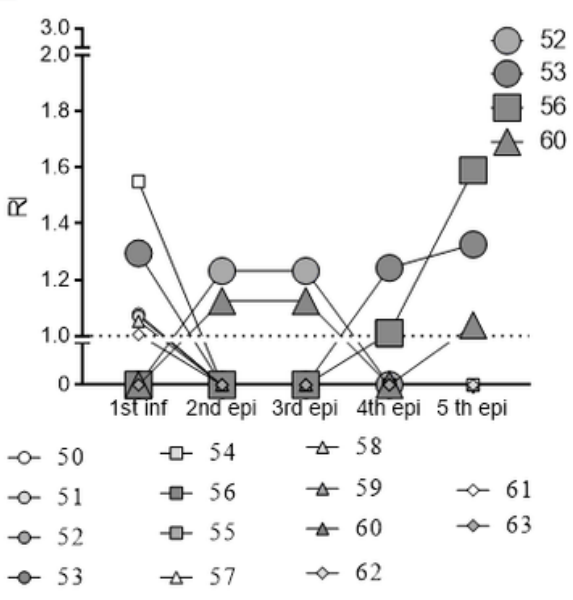

C

P3

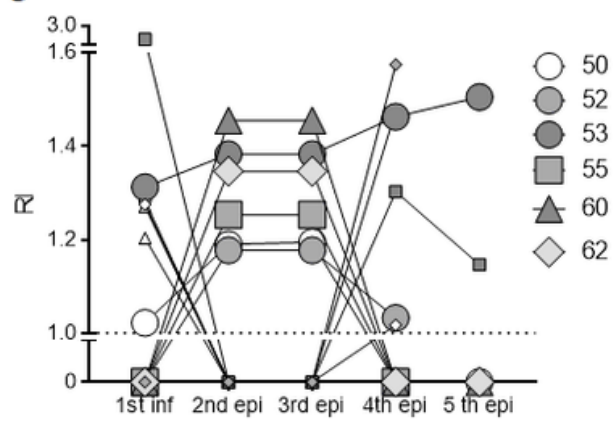

F

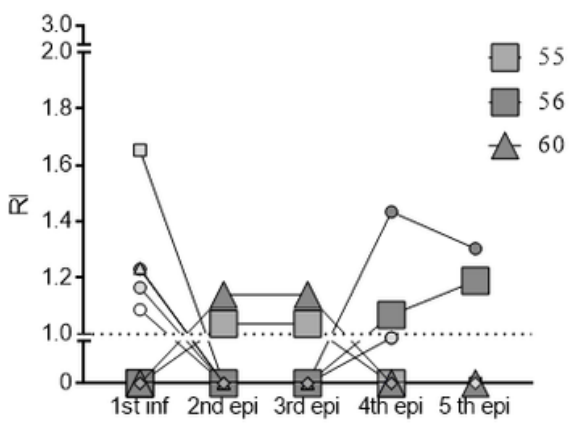

Figure 5

Serology of $P$. vivax-MSP1 Block 2 specific haplotype peptides of pregnant women who have had a primary infection and more than two malaria episodes. Of the women, 14 had two further episodes of malaria in the second and third trimesters and these were confirmed by microscopy on thick and thin smears of peripheral blood and PCR. Serology for IgM was performed against 6 haplotype-specific peptides of $P$. vivax MSP1 block 2 A) P1, B) P2, C) P3, D) P4, E) P5 and F) P6. Each woman was represented by a symbol and to the right of each graph are women who maintained or increased IgM levels on relapse relative to the initial infection. Dashed lines positivity in relation to cutoff values for each peptide calculated by mean absorbance for samples from 10 blood donors who had had no previous malaria infections, plus three standard deviations. Each woman was represented by a symbol (see below). Those women who maintained or increased IgM levels on relapse relative to the initial infection, their respective symbols have been increased and showed to the right of each graph. 

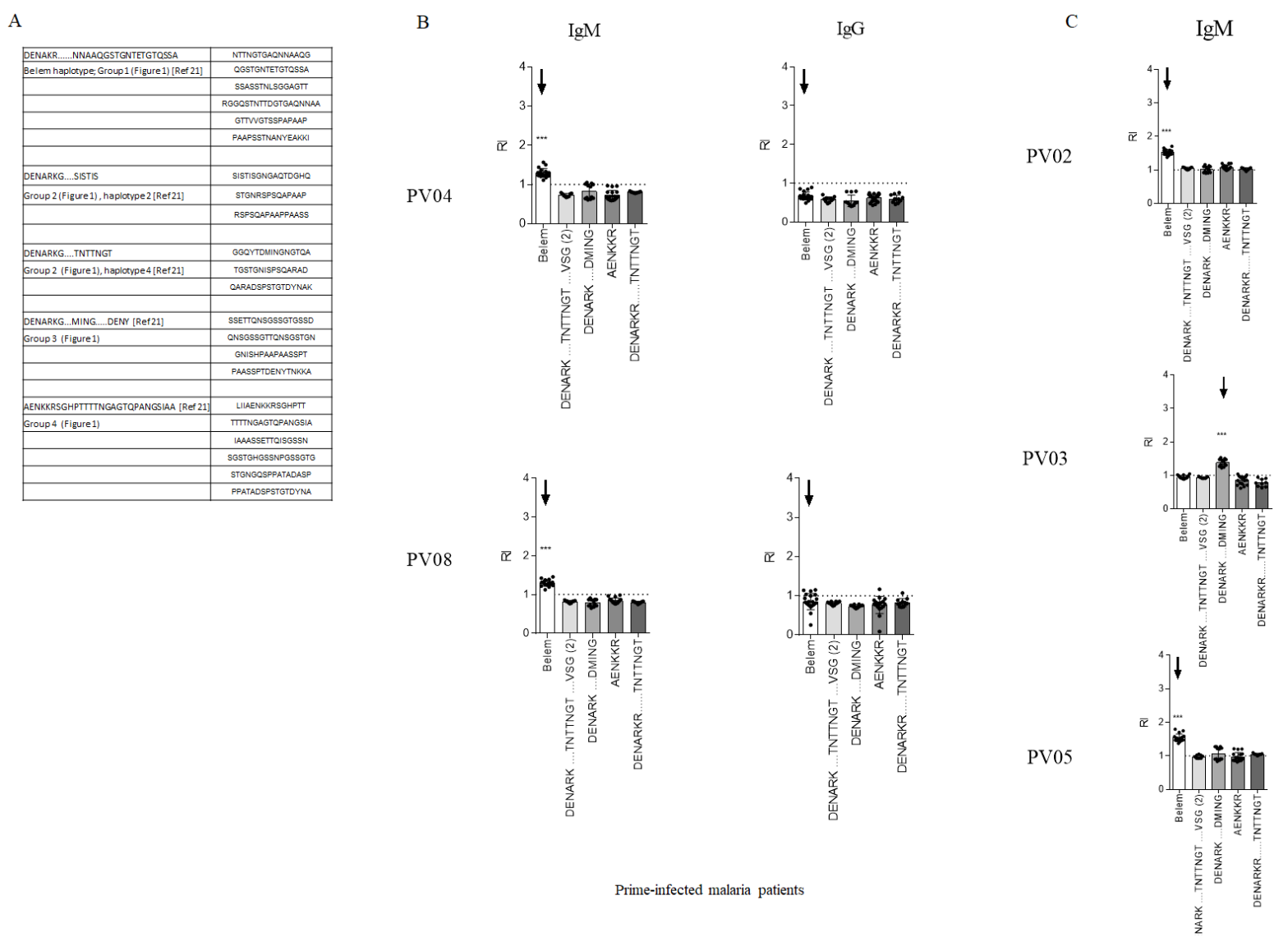

IgG

Prime-infected malaria patients

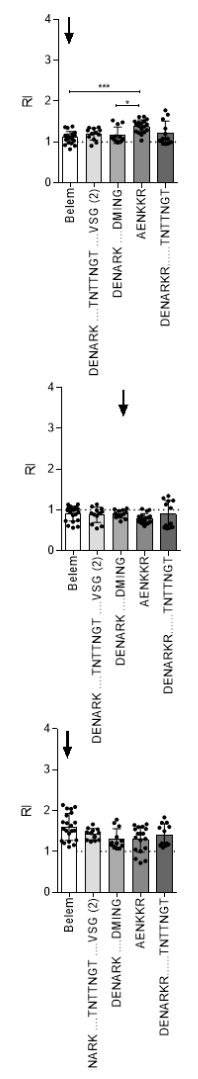

\section{Figure 6}

Amplicon deep sequencing (ADS) and specific haplotype serology. A) new superimposed peptide panel mapping the complete sequences of the main MSP1 Block 2 haplotypes of P. vivax. The Block 2 amplicon deep sequencing (ADS) technique determined that infections were by only one clone based on the Block 2 haplotype of MSP1. B) Arrows indicated the MSP1 Block 2 haplotype detected by ADS in two prime-infected P. vivax malaria patients. Comparison of IgM and IgG reactivities between haplotypespecific peptides corresponding to each clone identified by ADS and others haplotype ones. C) Serology of 3 patients (PV02, PV03 and PV05) who were infected by only one clone based on the Block 2 haplotype of MSP1. Comparison of IgM and IgG reactivity between peptides corresponding to the clone of the current infection (arrows) in relation to the peptides of other haplotypes was performed by nonparametric Kruskal-Wallis test. P-values: ${ }^{* \star *} p<0.0005$; ${ }^{* *} p<0.005$ and ${ }^{*} p<0.05$. 
A
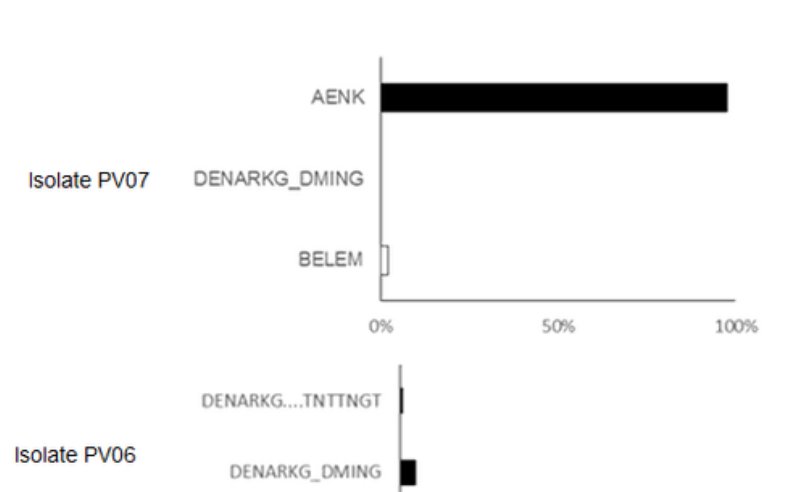

DENARKG..TNTINGT ....VSG(2)

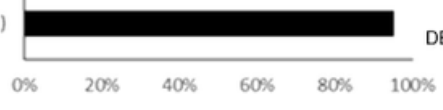

B
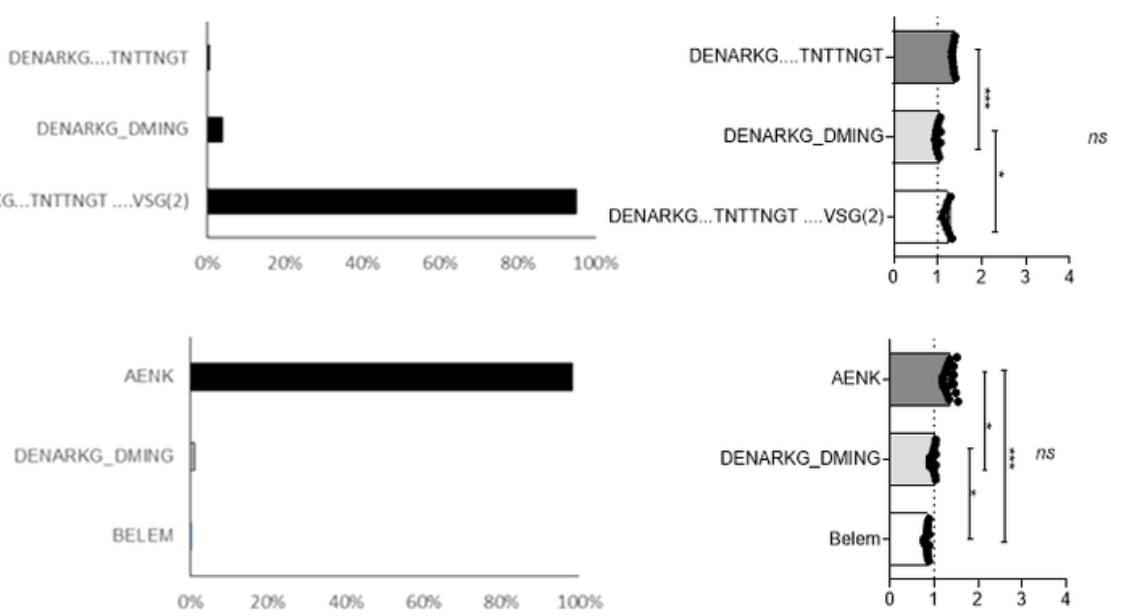

Figure 7
Frequencies of haplotypes by $\mathrm{ADS}$

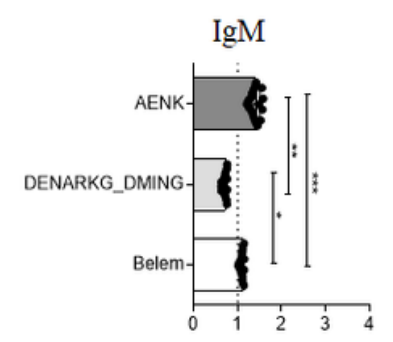

$\mathrm{C}$
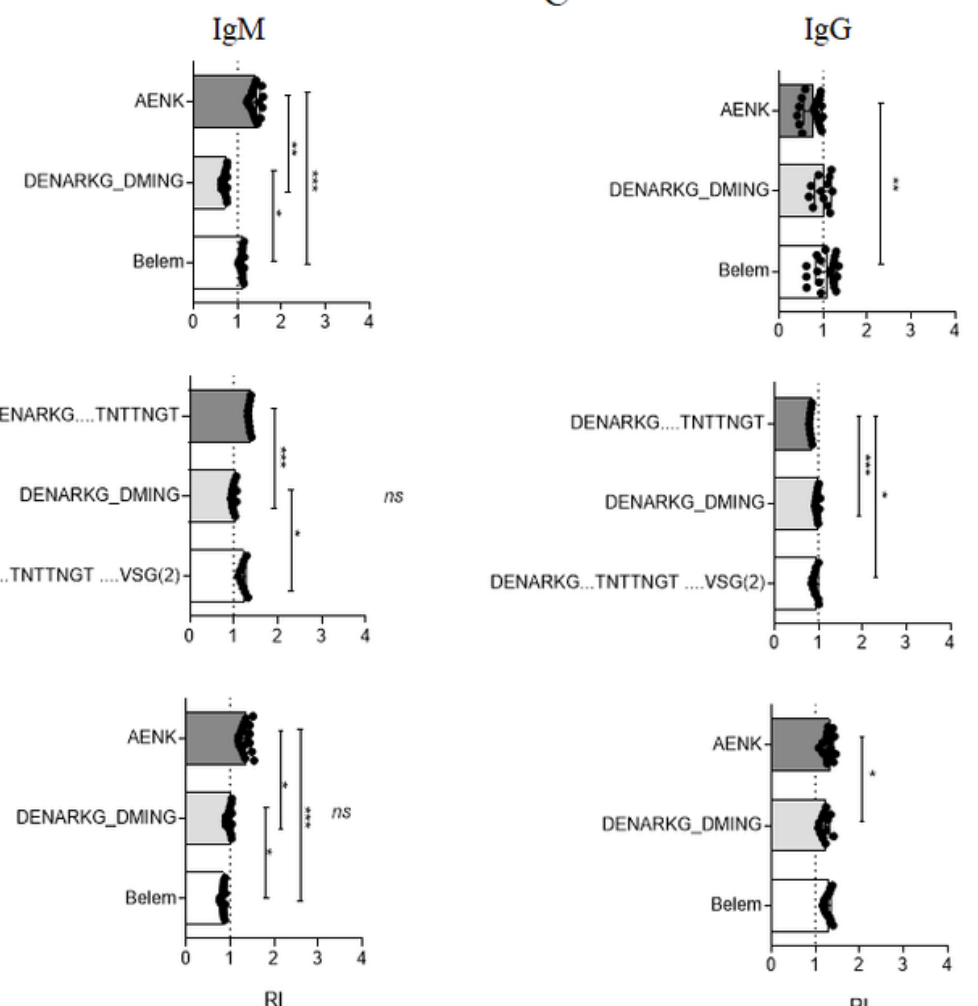

RI

Figure 7

ADS and specific haplotype serology as a new tool for the study of relapses in malaria caused by $P$. vivax. A) quantification of the reads of sequences obtained in the ADS of Block 2 in three patients who showed infection by 3 clones based on the haplotype of MSP1 Block 2 (for more details consult Materials and Methods). B) Comparison of IgM reactivity between haplotype-specific peptides corresponding to each clone identified by ADS. C) Comparison of IgG reactivity between haplotype-specific peptides corresponding to each clone identified by ADS. Analysis to assess which were different was performed by non-parametric Dunn's test for multiple comparisons

\section{Supplementary Files}

This is a list of supplementary files associated with this preprint. Click to download.

- Figure1SEpitopeprediction.tif 